\title{
Regional Changes in Mitochondrial Respiration in Acute Myocardial Ischemia \\ Comparison of the Inner and Outer Heart Muscles
}

\author{
Hiroyuki Minatoguchi, M.D., Sumiyasu Sekita, M.D., \\ Mikihiko Yokoyama, M.D., and Takashi KatagrRI, M.D.
}

\section{SUMmary}

Impairment of mitochondrial respiration in acute myocardial ischemia was studied in the inner and outer layers of canine heart muscle by the determination of oxidative phosphorylation and several respiratory enzymatic activities of isolated mitochondria. As early as $15 \mathrm{~min}$ after coronary ligation, the respiratory control ratio decreased as the result of a reduction in the oxygen consumption rate in state 3 to $72 \%$ of the control ratio in the inner layer. However, in the outer layer, it dropped to $74 \%$ after 1 to 2 hours. The oxygen consumption rate in state 4 and the $\mathrm{ADP} / \mathrm{O}$ ratio were not significantly altered in both cardiac sublayers. In parallel with a decrease in oxygen consumption rate in state $3, \mathrm{Mg}^{++}$dependent ATPase and DNP-stimulated ATPase activities of isolated mitochondria reduced significantly in both sublayers, followed by a sequential increase in $\mathrm{Mg}^{++}$-dependent ATPase activity. Succinate dehydrogenase activity increased in ischemia for 3 hours in the inner layer, and for 6 hours in the outer layer, respectively; cytochrome oxidase activity reduced in both sublayers during the same period. Mitochondrial respiration is impaired in acute myocardial ischemia much earlier in the inner layer by a decrease in oxygen consumption rate in state 3 , and there is a chronological delay in the development of ischemic mitochondrial changes in the outer myocardium.

\section{Additional Indexing Words:}

Acute myocardial ischemia Mitochondrial respiration Polarography Subendocardium Subepicardium Canine heart

From the Third Department of Internal Medicine, Showa University School of Medicine, Tokyo.

This work was in part supported by a Grant from the Ministry of Education, Science and Culture, Japan for 1981 .

Address for reprint: Hiroyuki Minatoguchi, M.D., Third Department of Internal Medicine, Showa University School of Medicine, 1-5-8 Hatanodai, Shinagawa-ku, Tokyo 142, Japan.

Received for publication April 1, 1983.

Manuscript revised August 26, 1983. 
$I^{1}$ $T$ is well known that cardiac muscle depends on aerobic metabolism at a rate of more than $95 \%$, which is accomplished solely by mitochondria. Soon after cessation of coronary blood flow, myocardial metabolism shifts from aerobic to anaerobic glycolysis. The cellular energy level falls abruptly, followed by a reduction in cellular $\mathrm{pH}$ as a result of decreased ATP, increased lactate, and related changes. The impairment of mitochondrial function in acute myocardial ischemia has long been one of the most interesting problems concerning the critical point of myocardial irreversible injury. For this reason many morphologic and biochemical studies have examined mitochondrial changes in the ischemic myocardium. ${ }^{1)-6)}$ It is now widely accepted that the subendocardium is injured earlier than the subepicardium in the acute stage of transmural ischemia,") which is observed as a subendocardial infarction in human cases. From this point of view, we divided the ischemic myocardium to the inner and outer sublayers after induction of experimental acute myocardial ischemia in the dog, and examined the respiration level of mitochondria from these tissues by determining the rate of mitochondrial oxidative phosphorylation, respiratory enzymatic activities and ATPase activities.

\section{Materials And Methods}

All the reagents used were reagent grade. Adenosine diphosphate (ADP), and adenosine triphosphate (ATP) were obtained from Sigma Chemical Co. (purities greater than 99\%). 2, 4-dinitrophenol (DNP) was from Wako Pure Chemical Industries.

Surgical procedures: Forty-five adult mongrel dogs, weighing 12 to $25 \mathrm{Kg}$, were anesthetized with intravenous injection of sodium pentobarbital (Nembutal ${ }^{\circledR}, 30 \mathrm{mg} / \mathrm{Kg}$ body weight). A left-sided thoracotomy was performed under positive pressure respiration with room air using a Harvard respirator. The anterior descending branch of the left coronary artery was isolated and ligated completely with a silk thread just below the first diagonal branch. The occurrence of transmural myocardial ischemia was confirmed by a continuous ST segment elevation of more than $0.5 \mathrm{mV}$ in the leads near $V_{3}$ and $\mathrm{V}_{4}$. Four to 5 dogs were subjected to each period of ischemia (15, 30 and 60 min, and 2, 3, 4, 6 and 12 hours after coronary ligation) under Nembutal anesthesia. In 5 sham operated dogs, the coronary artery was isolated but not ligated. After the appropriate survival time, the beating heart was immediately excised and washed briefly with an ice-cold solution containing $0.21 \mathrm{M}$ mannitol, $0.07 \mathrm{M}$ sucrose and $0.0001 \mathrm{M}$ ethylenediaminetetraacetate

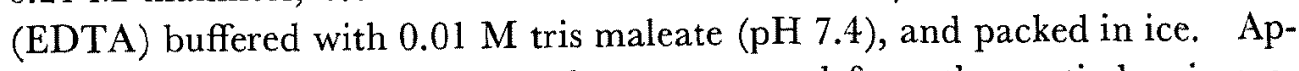
proximately $4 \mathrm{Gm}$ of heart muscle was removed from the postischemic cya- 
notic portion of the anterior left ventricular wall, including the anterior portion of the interventricular septum. The non-ischemic inferior portion of the left ventricle was used as a control. The ischemic myocardium was divided into 2 parts in the middle of heart muscle and they were designated the subendocardium and the subepicardium.

Mitochondrial preparation: The preparation of mitochondria was performed by the modified method of Chance and Hagihara, ${ }^{81}$ utilizing crystalline protease (Nagarse, Nagase Co. Ltd.). All the procedures were carried out at $4^{\circ} \mathrm{C}$ unless otherwise mentioned. Briefly, myocardial tissue was chopped with scissors, minced fincly with a stainless steel razor blade, and homogenized gently in 5 volumes of the extraction medium containing $0.21 \mathrm{M}$ mannitol, $0.07 \mathrm{M}$ sucrose, $0.0001 \mathrm{M}$ EDTA, $0.01 \mathrm{M}$ tris- $\mathrm{HCl}(\mathrm{pH} 7.4)$ and $5 \mathrm{mg} / \mathrm{Gm}$ of crystalline protease with a loose teflon-glass homogenizer in 5 strokes. The homogenate was kept in ice for $20 \mathrm{~min}$ and spun at $9,000 \times \mathrm{G}$ for $1 \mathrm{~min}$. After an addition of the solution without protease, the suspension was further homogenized slowly at about $500 \mathrm{rpm}$ with a regular teflon-glass homogenizer. The homogenate was spun at $500 \times \mathrm{G}$ for $5 \mathrm{~min}$ and the supernatant was centrifuged at $9,000 \times \mathrm{G}$ for $10 \mathrm{~min}$ twice. The precipitate was resuspended in a small volume of the medium. Protein concentration was determined by a biuret procedure using bovine serum albumin as a standard.

Measurement of oxidative phosphorylation: Mitochondrial oxidative phosphorylation was measured with an oxygen electrode (Oxygen Consumption Recorder PO-100A, Yanagimoto Mfg. Co. Ltd.), according to the method of Hagihara, ${ }^{9}$ in a reaction medium containing $0.01 \mathrm{M} \mathrm{KCl}, 0.0001 \mathrm{M}$ EDTA,

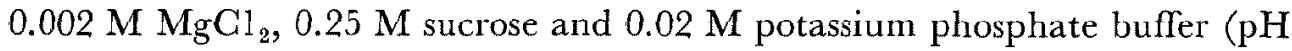
7.2) at $25^{\circ} \mathrm{C}$. Succinate was used as a substrate and ADP was added to estimate oxidative phosphorylation. Oxygen consumption rates in states 3 and 4, respiratory control ratio and $\mathrm{ADP} / \mathrm{O}$ ratio were detcrmined from a polarographic record by the method of Chance and Williams. ${ }^{10}$ )

Measurements of ATPase activity: Mitochondrial ATPase activity was examined by the modified method of Pullman et al ${ }^{11}$ in a medium containing $0.21 \mathrm{M}$ sucrose, $0.02 \mathrm{M} \mathrm{KCl}, 0.001 \mathrm{M} \mathrm{DNP}$ or $0.03 \mathrm{M} \mathrm{MgC1}_{2}, 0.02 \mathrm{M}$ trismaleate $\left(\mathrm{pH} \mathrm{7.2)}\right.$ and $3 \mathrm{mM} \mathrm{ATP}$ at $25^{\circ} \mathrm{C}$. The amount of phosphate liberated in the reaction was assayed by the method of Fiske and SubbaRow. ${ }^{12}$ )

Determination of succinate dehydrogenase $(S D H)$ activity: SDH activity was determined by the modified method of Singer et al. ${ }^{13)}$ The reaction was carried out in a medium containing $60 \mathrm{mM}$ phosphate buffer $(\mathrm{pH} 7.6), 1 \mathrm{mM}$ $\mathrm{KCN}, 72 \mu \mathrm{M}$ 2,6-dichlorophenolindophenol (DCIP), $0.1 \mathrm{mM}$ phenazine methosulphate, $0.75 \mathrm{mM} \mathrm{CaC1}_{2}$ and $0.02 \mathrm{M}$ succinate at $25^{\circ} \mathrm{C}$. Enzymatic activity was expressed as $\mu$ moles DCIP reduced $/ \mathrm{mg}$ protein $/ \mathrm{min}$. 


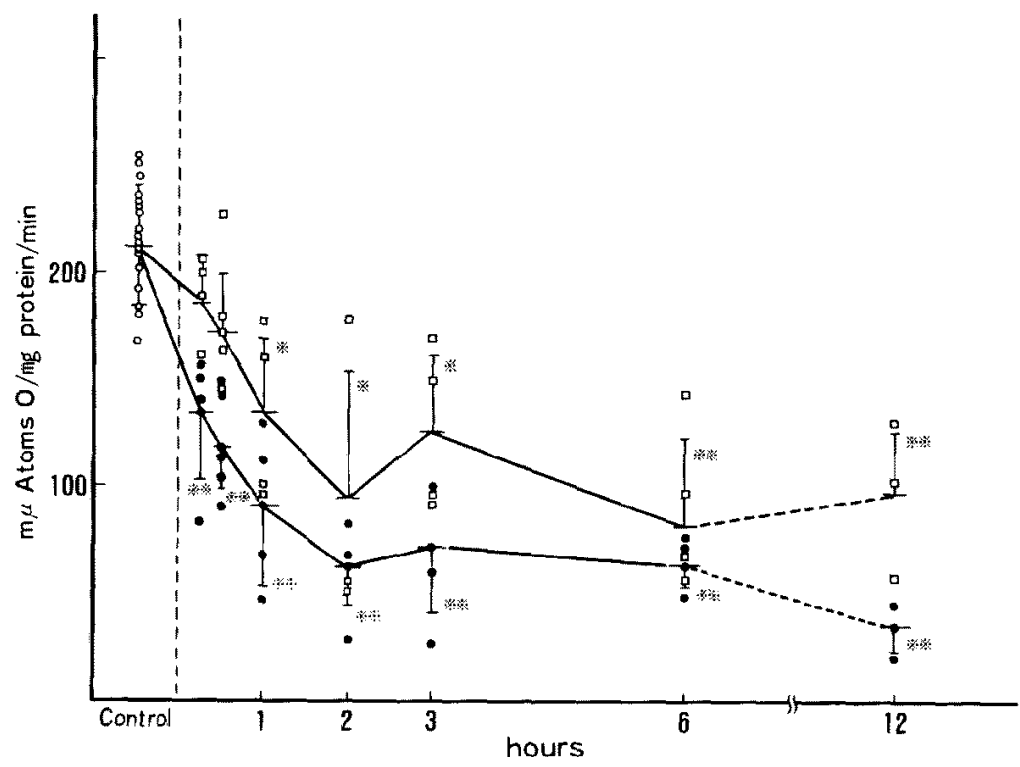

Fig. 1. Oxygen consumption rate in state 3 of mitochondria from the ischemic canine heart. Closed circles and open squares indicate the rates in the inner and outer layer, respectively. The reaction mixture contained $0.01 \mathrm{M} \mathrm{KCl}, 0.0001 \mathrm{M}$ EDTA, $0.002 \mathrm{M} \mathrm{MgCl}_{2}, 0.25 \mathrm{M}$ sucrose and $0.02 \mathrm{M}$ potassium phosphate buffer $(\mathrm{pH} 7.2)$ at $25^{\circ} \mathrm{C}$. Values are expressed as mean \pm SD. $※ p<0,01, ※ x<0.001$.

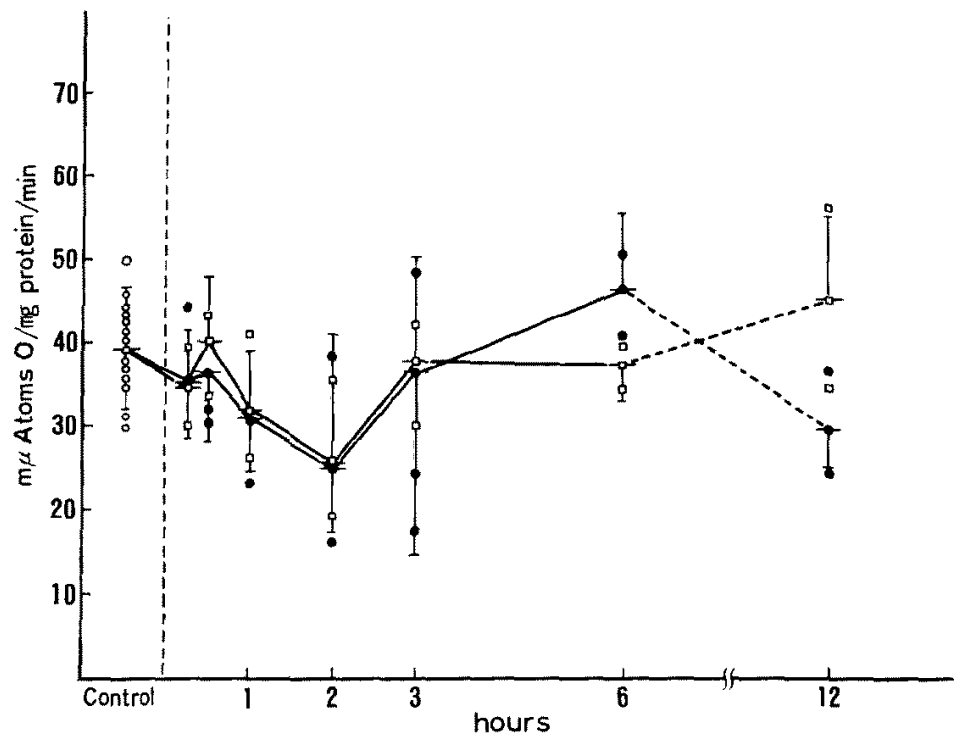

Fig. 2. Oxygen consumption rate in state 4 of mitochondria from the ischemic canine heart. Closed circles and open squares indicate the rates in the inner and outer layer, respectively. The reaction mixture is described in Fig. 1. 


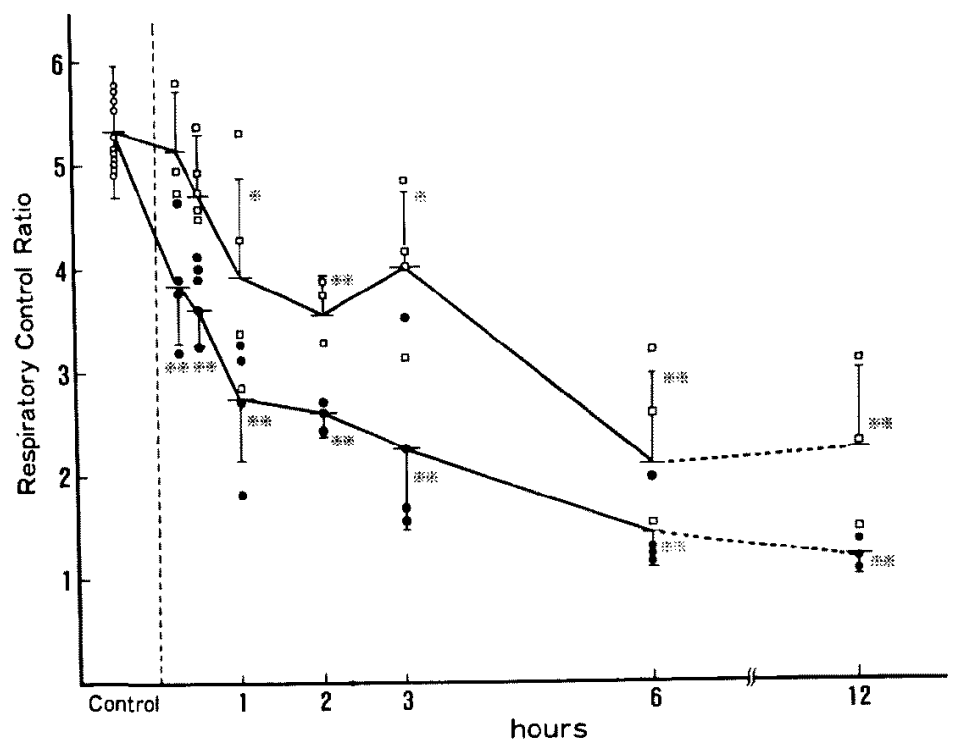

Fig. 3. Respiratory control ratio of mitochondria from the ischemic canine heart. Closed circles and open squares indicate the rates in the inner and outer layer, respectively. Values are expressed as mean \pm SD. $※ p<0.01$, ※p $<0.001$.

Determination of cytochrome oxidase activity: Cytochrome oxidase activity was determined using bovine cytochrome $\mathrm{C}$ as a substrate, according to the modified method of Orii et al. ${ }^{14)}$ Enzymatic activity was expressed as specific activity/mg protein $/ \mathrm{sec}$ at $25^{\circ} \mathrm{C}$.

Results are expressed as mean $\pm \mathrm{SD}$ of number of experiments indicated. Statistical analyses were performed using Student's t-test.

\section{Results}

Electron microscopic observations of the mitochondrial fraction revealed that contamination from other organelles was very low in mitochondrial fractions from the both non-ischemic and ischemic heart muscle (not illustrated). The respiratory functions of mitochondria from the non-ischemic heart muscles were not statistically different in each stage of ischemia, and also not different from those of the sham-operated dogs. Therefore the data in the non-ischemic myocardia are summarized as the control.

Fig. 1 shows the oxygen consumption rate in state $3.213 .8 \pm 25.3 \mathrm{~m} / \mu$ Atoms $\mathrm{O} / \mathrm{mg}$ protein/min was exhibited in the non-ischemic myocardium. In the inner layer, $15 \mathrm{~min}$ after coronary ligation, the oxygen consumption rate decreased significantly to $63 \%$ of the control rate $(\mathrm{p}<0.001)$. It con- 


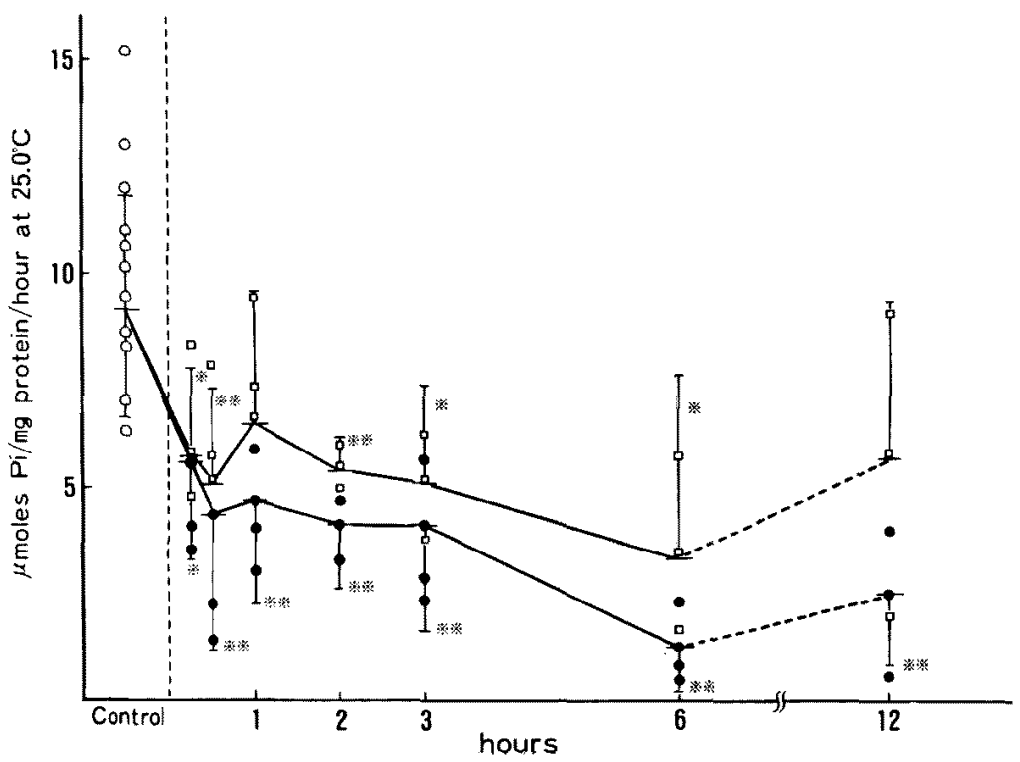

Fig. 4. DNP-stimulated ATPase activity of mitochondria from the ischemic canine heart. Closed circles and open squares indicate the rates in the inner and outer layer, respectively. The reaction mixture contained

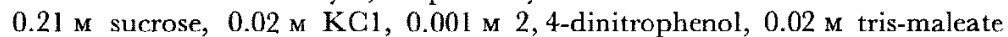
(pH 7.2) and $0.003 \mathrm{M} \mathrm{ATP}$ at $25^{\circ} \mathrm{C}$. Values are expressed as mean $\pm \mathrm{SD}$. $※ \mathrm{p}<0.01, \quad \approx * \mathrm{p}<0.001$.

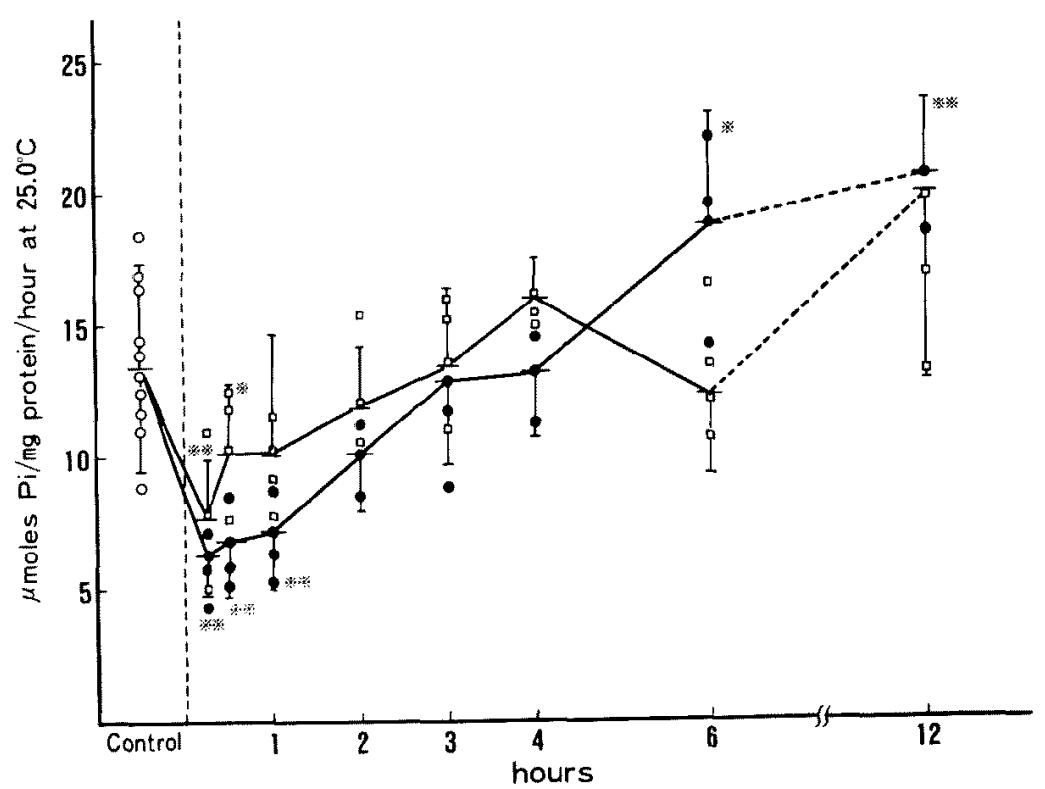

Fig. 5. $\mathrm{Mg}^{++}$-dependent ATPase activity of mitochondria from the ischemic canine heart. Closed circles and open squares indicate the rates in the inner and outer layer, respectively. The reaction mixture contained $0.21 \mathrm{M}$ sucrose, $0.02 \mathrm{M} \mathrm{KCl,} 0.03 \mathrm{M} \mathrm{MgCl}_{2}, 0.02 \mathrm{M}$ tris-maleate ( $\mathrm{pH} \mathrm{7.2)}$ and $0.003 \mathrm{M}$ ATP at $25^{\circ} \mathrm{C}$. Values are expressed as mean \pm SD. $\aleph_{p}<0.01$, $※ \approx p<0.001$. 


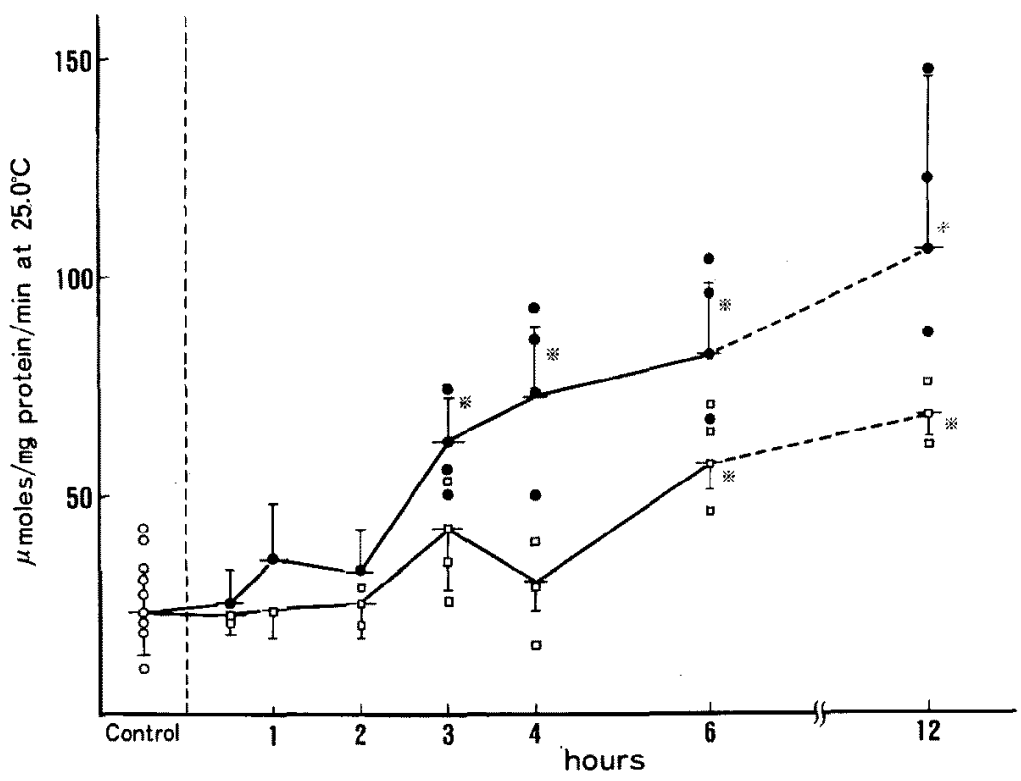

Fig. 6. Succinate dehydrogenase activity of mitochondria from the ischemic canine heart. Closed circles and open squares indicate the rates in the inner and outer layer, respectively. The rcaction mixture contained $0.06 \mathrm{~m}$ phosphate buffer ( $\mathrm{pH} 7.6$ ), $0.001 \mathrm{~m} \mathrm{KGN,} 72 \mu \mathrm{M}$ 2, 6-dichlorophenolindophenol, $0.1 \mathrm{~mm}$ phenazine methosulphate, $0.75 \mathrm{~mm} \mathrm{CaCl} 1_{2}$ and $0.02 \mathrm{M}$ succinate at $25^{\circ} \mathrm{C}$. Values are expressed as mean \pm SD. $※ p<0.01$.

tinued to decrease during 12 hours of ischemia. In the outer layer, the oxygen consumption rate in state 3 decreased more slowly than in the inner layer, falling to $62 \%$ of the control rate at 1 hour after coronary ligation.

The oxygen consumption rate in state 4 is shown in Fig. 2. The control value was $39.2 \pm 7.3 \mathrm{~m} \mu$ Atoms $\mathrm{O} / \mathrm{mg}$ protein $/ \mathrm{min}$. In the ischemic heart muscle, the rate in state 4 was not significantly altered in either sublayer.

The respiratory control ratio (RC), which is the ratio of the rates in state 3 and state 4 , decreased significantly to $72 \%$ of the control ratio at $15 \mathrm{~min}$ after coronary ligation in the inner layer and to $74 \%$ at 1 to 3 hours in the outer layer, and the $\mathrm{RC}$ decreased monotonically during 12 hours of ischemia (Fig. 3). By contrast, the $\mathrm{ADP} / \mathrm{O}$ ratio was not changed significantly either in the inner or in the outer layers.

The DNP-stimulated ATPase and $\mathrm{Mg}^{++}$-dependent ATPase activities are shown in Figs. 4 and 5, respectively. The DNP-stimulated ATPase activity was $9.20 \pm 2.59 \mu$ moles $\mathrm{Pi} / \mathrm{mg}$ protein/hour and the $\mathrm{Mg}^{++}$-dependent ATPase activity was $13.47 \pm 3.92 \mu$ moles $\mathrm{Pi} / \mathrm{mg}$ protein/hour in the control myocardium. The ADP-stimulated ATPase activity decreased significantly to $61 \%$ of the control activity in the inner layer and to $62 \%$ of the control in the outer 


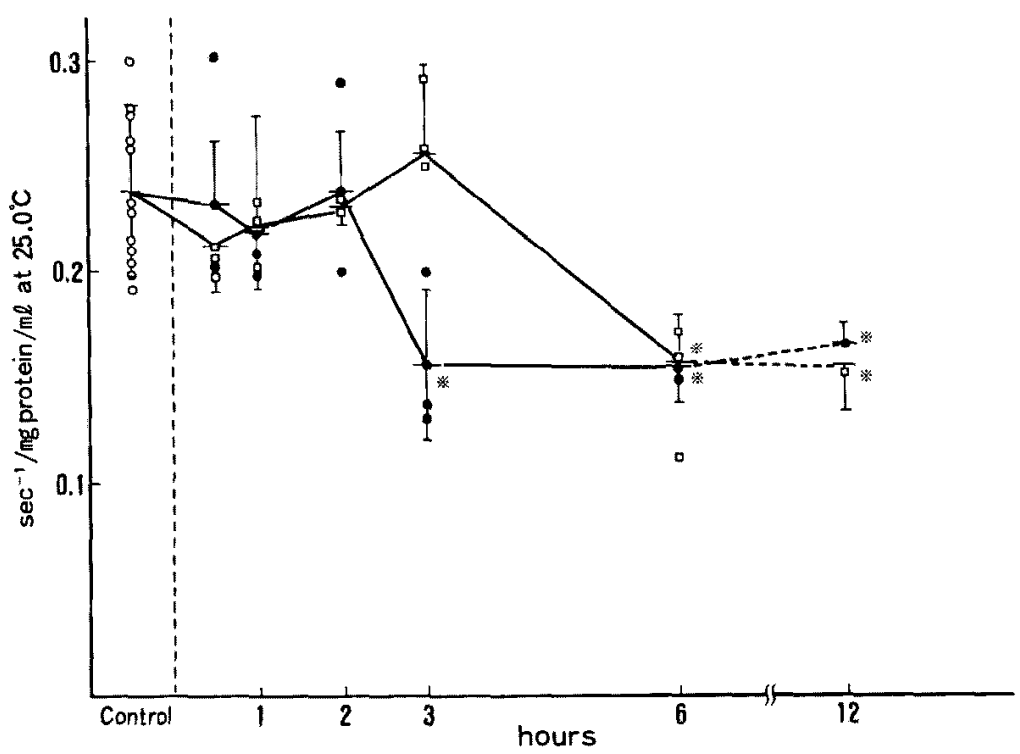

Fig. 7. Cytochrome oxidase activity of mitochondria from the ischemic canine heart. Closed circles and open squares indicate the rates in the inner and outer layer, respectively. The reaction mixture contained $0.15 \mathrm{M}$ phosphate buffer ( $\mathrm{pH} 6.0$ ) and $0.015 \mathrm{M}$ cytochrome $\mathrm{C}$ at $25^{\circ} \mathrm{G}$. Values are expressed as mean \pm SD. $※ p<0.01$.

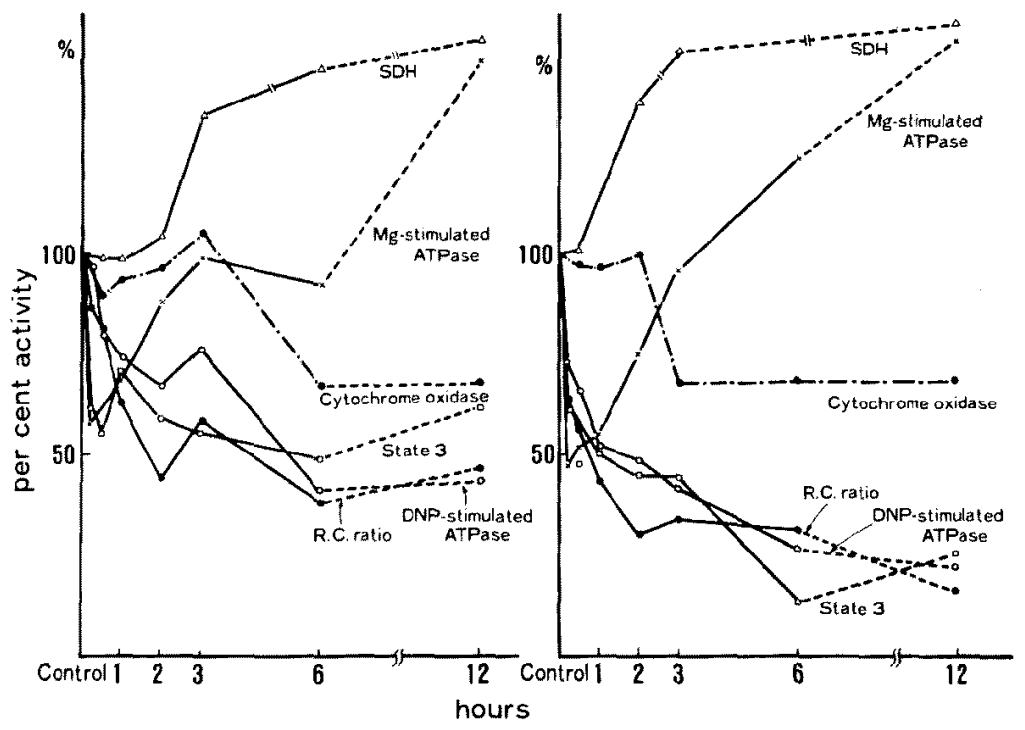

Fig. 8. Percent activities of parameters of mitochondrial respiration in the ischemic canine heart. The inner layer data of the ischemic myocardium are shown in the right panel and the outer layer data on the left panel. 
layer at $15 \mathrm{~min}$ after coronary ligation $(\mathrm{p}<0.001)$. At $30 \mathrm{~min}$, they were $47 \%$ and $55 \%$ of the non-ischemic heart muscle controls for the inner and outer layers, respectively. On the other hand, Mgt+-dependent ATPase activity was initially reduced to $47 \%$ of the control activity in the inner layer and to $57 \%$ in the outer layer at $15 \mathrm{~min}$ after coronary ligation. However, after 1 to 2 hours the activities rose steadily to reach $153 \%$ of the control myocardium value in the inner layer and $149 \%$ of the outer layer control at 12 hours.

SDH activity is shown in Fig. 6. The control myocardial activity was $23.41 \pm 10.73 \mu$ moles DCIP/mg protein. The activity of the inner layer remained in the control level until at 2 hours after coronary ligation, then increased rapidly after 3 to 4 hours. The increased activity reached $268 \%$ of the control value at 3 hours. The activity of the outer layer did not change from $15 \mathrm{~min}$ to 4 hours, and increased to $247 \%$ at 6 hours. SDH activities kept increasing through 12 hours after coronary ligation both in the inner and outer layers.

Cytochrome oxidase activity is shown in Fig. 7. The control value was $0.238 \pm 0.041 / \mathrm{mg}$ protein $/ \mathrm{sec}$. As in the case of SDH activity, cytochrome oxidase activity remained at the control level from $15 \mathrm{~min}$ to 2 hours after coronary ligation in the inner layer, and from $15 \mathrm{~min}$ to 3 hours in the outer layer. The activities of both layers then began to decrease, reaching $65 \%$ of control at 3 hours in the inner layer $(p<0.01)$, and $66 \%$ at 6 hours in the outer layer $(\mathrm{p}<0.01)$, respectively. These results are summarized in Fig. 8 as percent change for each parameter.

\section{Discussion}

Mitochondrial structure and function in acute ischemic myocardial injury have received considerable attention because mitochondria are the sole microorganelles conducting aerobic metabolism, which accounts for more than $95 \%$ of the energy needs of cardiac muscle.

The utilization of alkaline protease in the preparation procedure, introduced by Chance and Hagihara, ${ }^{8}$ results in a preparation containing both subsarcolemmal and interfibrillar mitochondria without impairment of mitochondrial function. ${ }^{15)}$ In addition, this method reduces contamination by the digestion with alkaline protease. Electron microscopic observation of the mitochondrial fraction revealed satisfactory purity both in the non-ischemic and ischemic heart muscles.

Since the 1950s, morphologic changes in mitochondria in myocardial ischemia have been reported often in the literature. Jennings et $\mathrm{al}^{2,3), 16)}$ observed swollen mitochondria with disordered cristae at 15 to 30 min after coro- 
nary ligation; the appearance of intramitochondrial dense deposits at $40 \mathrm{~min}$ was defined as the first cellular sign of irreversible ischemia. On the biochemical aspect, reductions in oxygen consumption rate and respiratory control ratio were noted over 12 hours after myocardial ischemia. ${ }^{6)}$ A reduction in the oxygen consumption rate in state 3 was reported by Schwartz et al ${ }^{17}$ in the ischemic myocardium 7 days after coronary ligation, and later at $60 \mathrm{~min}$ by Jennings et al. ${ }^{18}$ ) By contrast, Yamagami et al ${ }^{19)}$ observed a deterioration of the oxygen consumption rate in state 4 . In this study, the disturbance of mitochondrial respiration in myocardial ischemia was attributed to a reduction in the oxygen consumption rate in state 3 . The inner myocardium was affected much earlier by ischemia than the outer layer (as early as $15 \mathrm{~min}$ after coronary ligation). By contrast, Hayashi et al ${ }^{20)}$ found no differences in the respiratory activities between the inner and outer layers at $30 \mathrm{~min}$ after occlusion of one of the small branches of the anterior descending artery.

Regarding these metabolic differences between the subendocardium and the subepicardium, Griggs and co-workers have reported that regional blood flow is smaller in the subendocardium, ${ }^{21-23)}$ the capillary distribution is lowered to a greater extent ${ }^{24), 25}$ and tissue level of ATP decreased more in the ischemic state in the subendocardium than in the subepicardium. ${ }^{26}$ ) The delay in the development of ischemic changes in the outer layer in this study may be a function of these anatomical and physiologic differences in heart muscle.

In our previous reports, a simultaneous reduction in $\mathrm{Ca}^{++}$-stimulated ATPase activity and the $\mathrm{Ca}^{++}$-uptake rate of the sarcoplasmic reticulum were observed in ischemia for 90 to $180 \mathrm{~min},{ }^{27}$ ) and a decrease in sarcolemmal $\mathrm{Na}^{+}-\mathrm{K}^{+}$-ATPase was observed within 60 to $90 \mathrm{~min}$ after coronary ligation. ${ }^{28}$ Mitochondrial ischemic changes developed much earlier than these membrane effects. It should be taken into consideration that impairment of mitochondrial function induces a decrease in the production of ATP, and this lowered ATP level would facilitate the degradation of the membrane system since Jennings et al recognized the close relationship between lowered ATP and the appearance of fine structural changes in acute myocardial ischemia. ${ }^{29}$ )

Hagihara has described 3 types of disturbances of oxidative phosphorylation with polarographic patterns, a disturbance of oxidation, a disturbance of phosphorylation and an uncoupling of oxidative phosphorylation. ${ }^{30}$ The polarographic pattern of ischemic heart mitochondria in the present study, a reduction in respiration rate in state 3 with a normal range of state 4 , is a disturbance of phosphorylation. This also supported by changing patterns of mitochondrial ATPase activities, since DNP-stimulated ATPase activity was reduced already in ischemia for $15 \mathrm{~min}$, whereas $\mathrm{Mg}^{++}$-dependent ATPase ac- 
tivity increased after an initial reduction in the inner layer. ${ }^{30)}$ It is possible that this increase in $\mathrm{Mg}^{++}$-dependent ATPase activity exhausts the remaining ATP in mitochondria in the ischemic heart muscle and exacerbates the ischemic injury.

The SDH and cytochrome oxidase activities were retained until 3 hours after coronary ligation, even in the inner layer. In the recent study by Rouslin and Millard, ${ }^{31)}$ an impairment of mitochondrial phosphorylating respiration was observed as a lesion in the NADH-coenzyme $Q$ reductase segment of the electron transport chain. Reduction in the activities of complex I was also recognized in congestive heart failure. ${ }^{32}$ Even though SDH and cytochrome oxidase activities were unchanged, impairment in the electron transport system would have occurred from the initial state of myocardial ischemia. The tight binding of these enzymes to the mitochondrial inner membrane may account for this phenomenon, ${ }^{33)}$ or latent $\mathrm{SDH}$ activity might have been activated by a reduction in inhibitors such as malonate in myocardial ischemia. ${ }^{34}$

\section{ACKNOWLEDGments}

The authors are very grateful to Prof. Hirokazu Niitani of Showa University and Prof. Tokuhiko Higashi of Tsukuba University for their kind guidance and encouragement. They are also greatly indebted to Drs. Yasufumi Sasai, Youichi Kobayashi and Youichi Takeyama for their kind collaboration.

\section{REFERENCES}

1. Jennings RB, Kaltenbach JP, Smetters GW: Enzymatic changes in acute myocardial ischemic injury. Arch Pathol 64: 10, 1957

2. Jennings $\mathrm{RB}$, Baum $\mathrm{JH}$, Herdson PB: Fine structural changes in myocardial ischemic injury. Arch Pathol 79: 135, 1965

3. Shen AC, Jennings RB: Myocardjal calcium and magnesium in acute ischemic injury. Am J Pathol 67: 417, 1972

4. Ekholm R, Kerstell J, Olsson R, Rudenstam CM, Svanborg A: Morphologic and biochemical studies of dog heart mitochondria after short periods of ischemia. Am J Cardiol 22: 312, 1968

5. Kuramoto K: Pathological, histochemical and electrocardiographic studies of experimental myocardial infarction. Jpn Circulat J 22: 722, 1959

6. Calva E, Mujica A, Bistent A, Sodi-Pallares D: Oxidative phosphorylation in cardiac infarct. Effect of glucose-KC1-insulin solution. Am J Physiol 209: 371, 1965

7. Jennings RB, Sommers HM, Smyth GA, Flack HA, Linn H: Myocardial necrosis induced by temporary occlusion of a coronary artery in the dog. Arch Pathol 70: 68, 1960

8. Chance B, Hagihara B: Direct spectroscopic measurements of interaction of components of the respiratory chain with ATP, ADP, Phosphate and uncoupling agents. Fifth International Congress of Biochemistry, Pergamon Press, MacMillan Co, New York, p 3-33, 1963

9. Hagihara B: Techniques for the application of polarography to mitochondrial respiration. 
Biochim Biophys Acta 46: 134, 1961

10. Chance B, Williams GR: Respiratory enzymes in oxidative phosphorylation. I. Kinetics of oxygen utilization. J Biol Chem 217: 383, 1955

11. Pullman ME, Penefsky HS, Datta A, Racker E: Partial resolution of the enzymes catalyzing oxidative phosphorylation. I. Purification and properties of soluble dinitrophenol-stimulated adenosine triphosphatase. J Biol Chem 235: 3322, 1960

12. Fiske CH, SubbaRow Y: The colorimetric determination of phosphorus, J Biol Chem 66: 375,1925

13. Singer TP, Kearney EB: Determination of succinic dehydrogenase activity, in Methods of Biochemical Analysis, Vol 4, Interscience Publishers Inc, New York, p 307, 1957

14. Orii Y, Okunuki K: Studies on Gytochrome a. XV Gytochrome oxidase activity of the Okunuki preparation and its activation by heat, alkali and detergent treatments. J Biochem 58: 561,1965

15. Matlieb MA, Rebman D, Ashraf M, Rouslin W, Schwartz A: Differential activities of putative subsarcolemmal and interfibrillar mitochondria from cardiac muscle. J Mol Cell Cardiol 13: 163, 1981

16. Jennings RB, Herdson PB, Sommers HM: Structural and functional abnormalities in mitochondria isolated from ischemic dog myocardium. Lab Invest 20: 548, 1969

17. Schwartz A, Wood JM, Allen JC, Bornet EP, Entman ML, Goldstein MA, Sordahl LA, Suzuki M: Biochemical and morphologic correlates of cardiac ischemia. I. Membrane system. Am J Cardiol 32: 46, 1973

18. Jennings $R B$, Ganote CE: Mitochondrial structure and function in acute myocardial ischemic injury. Circulat Res 38(Suppl I): I-80, 1976

19. Yamagami T, Morita Y, Yamamura Y: Mitochondrial respiration of experimentally produced ischemic heart muscle in dogs. Jpn Heart J 8: 132, 1967

20. Hayashi A, Abiko Y: The respiration of mitochondria in the inner and outer layers of dog myocardium. Folia Pharmacol Jpn 72: 483, 1976 (in Japanese)

21. Rivas F, Cobb FR, Bache RJ, Greenfield JC: Relationship between blood flow to ischemic regions and extent of myocardial infarction. Serial measurement of blood flow to ischemic regions in dogs. Circulat Res 38: 439, 1976

22. Moir TW, Debra DW: Effect of left ventricular hypertension, ischemia and yasoactive drugs on the myocardial distribution of coronary flow. Circulat Res 21:65, 1967

23. Griggs DM, Nakamura Y: Effect of coronary constriction on myocardial distribution of iodoantipyrine-131 I. Am J Physiol 215: 1082, 1968

24. Griggs DM, Tchokoev VV, Chen CC: Transmural differences in ventricular tissue substrate levels due to coronary constriction. Am J Physiol 222: 705, 1972

25. Leunissen RLA, Piatnek-Leunissen DA, Nakamura Y, Griggs DM: Regional metabolism of heart during reduced coronary flow. Circulation 33, 34(Suppl III): III-155, 1966

26. Gerdes AM, Callas G, Kasten FH: Differences in regional capillary distribution and myocyte sizes in normal and hypertrophic rat hearts. Am J Anat 156: 523, 1979

27. Toba K, Katagiri T, Takeyama Y: Studies on the cardiac sarcoplasmic reticulum in myocardial infarction. Jpn Circulat J 42: 447, 1978

28. Kobayashi $\mathrm{Y}$, Sasai $\mathrm{Y}$, Nakamura N, Katagiri T: Studies on the $\mathrm{Na}^{+}-\mathrm{K}^{+}$-ATPase in myocardial infarction. Jpn Circulat J 45: 1256, 1981

29. Jennings RB, Hawkins HK, Jowe JE, Hill ML, Klotman S, Reimer KA: Relation between high energy phosphate and lethal injury in myocardial ischemia in the dog. Am J Pathol 92: 187,1978

30. Hagihara B, Conelly JL, Shikama K, Oshino R, Okunuki K: Effects of antibiotics on respiratory and phosphorylative systems of mitochondria. Koso Kagaku Symposium 17: 58, 1962 (in Japanese)

31. Rouslin W, Millard RW: Canine myocardial ischemia. Defect in mitochondrial electron transfer complex I. J Mol Cell Cardiol 12: 639, 1980

32. Folkers $\mathrm{K}$, Littarru GP, Ho L, Runge TM: Evidence for a deficiency of coenzyme $Q_{10}$ in 
human heart disease. Internat J Vit Res 40: 380, 1970

33. Garroll BJ, Welman E: Loss of respiratory enzyme activity in anoxic myocardium. Effect of propranolol. J Mol Cell Cardiol 11: 1209, 1979

34. Quastel JH, Wooldridge WR: Some properties of the dehydrogenating enzymes of bacteria. Biochem J 22: 689, 1928 